\title{
Investigation of Anomalous Origin of Coronary Arteries in 8,366 Adult Patients Who Had Coronary Angiography: A Single Center Study
}

\author{
Fatma Yilmaz Coskun iD \\ Department of Cardiology, University of Gaziantep, Gaziantep, Turkey
}

ORCID iD of the author: F.Y.C. 0000-000I-904I-3682.

Cite this article as: Coskun FY. Investigation of anomalous origin of coronary arteries in 8,366 adult patients who had coronary angiography: A single center study. Cyprus J Med Sci. 2021; 6(3): 262-266.

\section{BACKGROUND/AIMS}

Congenital coronary anomalies usually do not cause clinical problems; however, some of them might be presented with serious clinical pictures such as sudden death. We investigated the prevalence and characteristics of anomalous origin of coronary artery (AOCA) in patients who had coronary angiography.

\section{MATERIAL and METHODS}

The coronary angiography reports of 8,366 patients at our center between January 2013 and October 2018 were reviewed. Angiography images of patients who were reported to have AOCA were reevaluated.

\section{RESULTS}

Fifteen of $8,366(0.18 \%)$ patients were found to have AOCA. The most commonly detected anomaly was anomalous origin of the circumflex artery (CX) originating from right coronary artery (RCA) or right sinus of Valsalva (RSV) in seven patients (prevalence $0.08 \%$ or $46.6 \%$ of all AOCA). Five patients showed a single coronary artery (prevalence $0.05 \%$ or $33.3 \%$ of all AOCA), which was arising from the RSV in three of them and from left sinus of Valsalva (LSV) in the rest of two. In two patients ( $0.02 \%$ or $13.3 \%$ of all AOCA), the left main coronary artery (LMCA) was originating from the RSV through separate ostium from the RCA. LMCA from the pulmonary artery was seen in one patient $(0.01 \%$ or $6.6 \%$ of all AOCA). Four patients were found to have coronary artery disease ( $26.6 \%$ of all AOCA) and two of them presented with acute coronary syndrome.

\section{CONCLUSION}

The prevalence of AOCA was found at $0.18 \%$ in the present study. The most commonly seen anomaly was the origin of CX artery from RCA or RSV.

Keywords: Coronary angiography, coronary artery anomaly, anomalous origin of coronary artery

\section{INTRODUCTION}

Coronary artery anomalies that consist of anomalous origin of a coronary arteries (AOCAs), myocardial bridge, and coronary fistula are commonly seen congenital cardiovascular anomalies. Many of the coronary artery anomalies are detected incidentally during coronary angiography, computed tomography, or autopsy at an incidence ranging between $0.17 \%$ and $2.2 \%$ in autopsy and also between 0.6 and $1.3 \%$ in patients who had coronary angiography. The incidence rate of one or more AOCA has been found at percentages ranging from $0.27 \%$ to $1.66 \%$ in patients undergoing coronary angiography and at $0.6 \%$ in autopsy series. Most of the congenital coronary anomalies usually do not cause clinical problems; however, some of them might be presented with serious clinical pictures such as sudden cardiac death, congestive heart failure, arrhythmia, myocardial infarction, and syncope. AOCA has been detected in almost one-third of sudden cardiac deaths among young adults and athletes. ${ }^{2,3}$ Furthermore, awareness of these anomalies is crucial as they could lead to complications during a coronary interventional procedure or a cardiac surgery.

The aim of our study was to investigate the prevalence and characteristics of AOCA in patients who had coronary angiography in our center. 
Table I. Characteristics and Prevalence of Anomalous Origin of Coronary Arteries $(n=15)$ in the Patient Population $(n=8,366)$

\begin{tabular}{|c|c|c|c|}
\hline $\begin{array}{l}\text { Origin of } \\
\text { Coronary Artery }\end{array}$ & $\mathbf{n}$ & $\begin{array}{c}\text { Prevalence, } \\
\%\end{array}$ & $\begin{array}{c}\text { Prevalence } \\
\text { Among all } \\
\text { Patients, \% }\end{array}$ \\
\hline CX from RCA & 4 & 26.6 & 0.04 \\
\hline CX from RSV & 3 & 20 & 0.03 \\
\hline Single CA & 5 & 33.3 & 0.05 \\
\hline RCA from LMCA & । & 6.6 & 0.01 \\
\hline RCA from distal CX & 1 & 6.6 & 0.01 \\
\hline LMCA from RCA & 3 & 20 & 0.03 \\
\hline LMCA from RSV & 2 & 13.3 & 0.02 \\
\hline $\begin{array}{l}\text { LMCA from PA } \\
\text { (ALCAPA) }\end{array}$ & 1 & 6.6 & 0.01 \\
\hline \multicolumn{4}{|c|}{$\begin{array}{l}\text { CX: circumflex artery, RCA: right coronary artery, RSV: right sinus of } \\
\text { Valsalva, CA: coronary artery, LMCA: left main coronary artery, PA: } \\
\text { pulmonary artery, ALCAPA: anomalous left coronary artery from the } \\
\text { pulmonary artery }\end{array}$} \\
\hline
\end{tabular}

\section{MATERIAL and METHODS}

The coronary angiography reports of 8,366 patients at our center between January 2013 and October 2018 were reviewed. The coronary angiography images of patients who were reported to have coronary anomaly were reevaluated by two experienced interventional cardiologists, and they reached an agreement on the origin of the anomalous coronary arteries. Coronary angiography indications were to investigate the coronary arteries in acute coronary syndromes or elective settings. Patients who had muscular bridge, coronary fistula, and/or complex congenital heart disease were not enrolled in the study. High "take-off" of coronary arteries, separate origin of conus or right ventricular branch in the right sinus of Valsalva (RSV), and the separate ostium of left anterior descending (LAD) and circumflex (CX) arteries in the left sinus of Valsalva (LSV) were regarded as a variant of normal anatomy, and they were not accepted as the AOCA. ${ }^{4}$ Epicardial coronary artery stenosis exceeding $50 \%$ was considered as coronary artery disease. Ethical approval was obtained from Gaziantep University Medical Faculty, Cardiology Department (study protocol code: 2018/33I).

\section{RESULTS}

Fifteen out of 8,366 patients $(0.18 \%)$ have been detected to have AOCA (Table I). The mean age of these 15 patients was 56.4 years, and six (40\%) of them were male. The most commonly detected anomaly was an anomalous origin of the CX originating from the right coronary artery (RCA) or RSV, which was found in seven patients (prevalence $0.08 \%$ or $46.6 \%$ of all AOCA). In four of these seven patients, CX was originated

\section{Main Points}

- Anomalous origin of a coronary arteries (AOCA) is a rare congenital cardiovascular anomalies as the prevalence was found at $0.18 \%$.

- Origin of circumflex (CX) artery directly from right coronary artery (RCA) or through a separate ostium from right sinus of Valsalva (RSV) is the most commonly seen AOCA.

- Anomalous origin of coronary arteries can complicate coronary interventions.

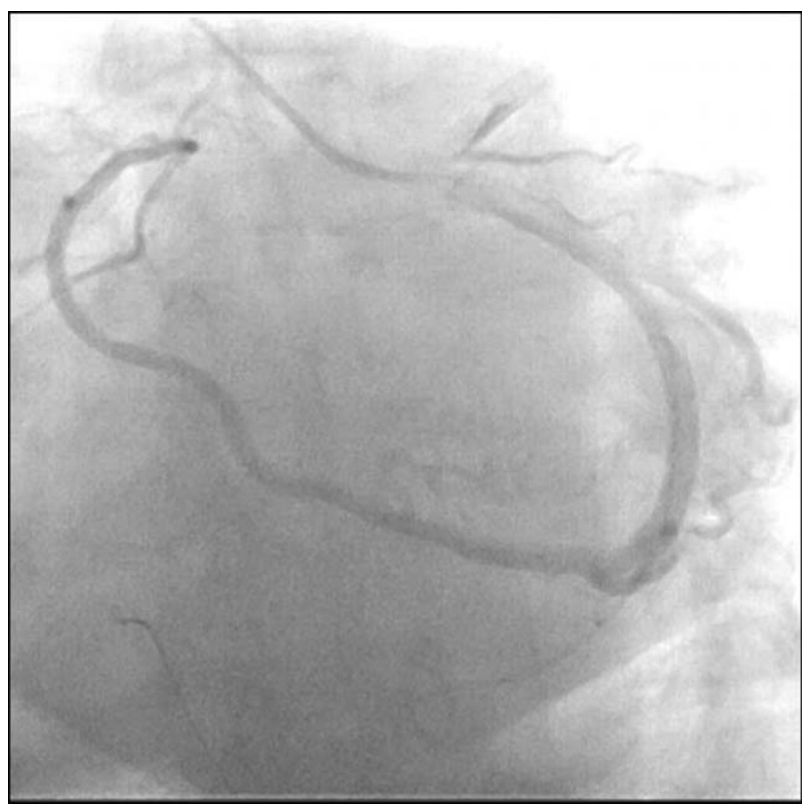

Figure I. Coronary angiography image of single coronary artery. RCA was originated from the distal of the LCX and it terminated near the RSV. RCA: Right Coronary Artery, RSV: Right Sinus of Valsalva

from the RCA $(0.04 \%$ or $26.6 \%$ of all AOCA), and in the rest of three patients, CX was found to be originated from a separate ostium in the RSV ( $0.03 \%$ or $20 \%$ of all AOCA). Single coronary artery was seen in five patients $(0.05 \%$ or $33.3 \%$ of all AOCA). It was originated from the RSV in three of them $(0.03 \%$ or $20 \%$ of all AOCA) and from the LSV in two of them $(0.02 \%$ or $13.3 \%$ of all $A O C A$ ). In one of the cases with single coronary artery of LSV origin, RCA was found to be originating from the distal of the CX and terminating near the RSV (Figure I). Another anomaly was LMCA originating from the RSV through separate ostium from RCA in two patients $(0.02 \%$ or $13.3 \%$ of all AOCA).

Anomalous left coronary artery from the pulmonary artery (ALCAPA) was detected in one patient $(0.01 \%$ or $6.6 \%$ of all AOCA). Coronary artery disease was detected in four patients with AOCA (26.6\% of all AOCA), and two of these patients presented with acute coronary syndrome.

\section{DISCUSSION}

In the present study, the AOCA prevalence was at $0.18 \%$, and the anomalous origin of the CX artery from RSV (prevalence $0.08 \%$ or $46.6 \%$ of all AOCA) was most commonly seen in one patient. CX was originated directly from RCA or through a separate ostium from RSV. This finding was in keeping with previously published series, reporting that the CX originating from RCA or RSV is the most common coronary artery anomaly with angiographic prevalence at ranging from 0.08 to $0.41 \%$. This anomaly might be important in the case of cardiac surgery; otherwise, it is thought to have little clinical importance. ${ }^{5-7}$ AOCA might be presented with angina, syncope, palpitations, dyspnea, or sudden cardiac death (SCD). The link between AOCA and ischemic symptoms has not been clearly defined yet. The available data could not demonstrate the direct relation between these anomalies and typical myocardial ischemiarelated signs and symptoms. ${ }^{8}$ For instance, a study has reported that myocardial ischemia-related signs and symptoms 


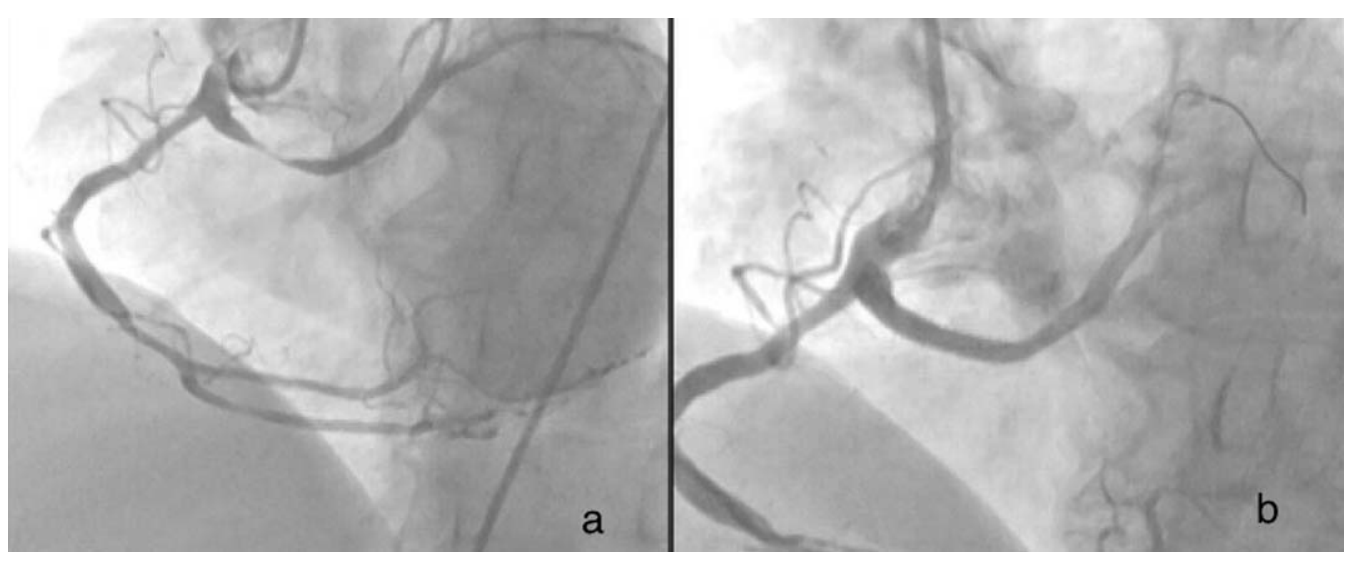

Figure 2. Coronary angiography images. (a) Single coronary artery was originating from RSV, and it was divided into RCA and LMCA. LMCA was long and giving two main branches as LAD and CX. LMCA was found to have stenosis around $90 \%$ severity in mid-segment. (b) After successful percutaneous coronary intervention with stent was performed. RCA, right coronary artery; LMCA, left main coronary artery; LAD, left anterior descending artery; CX, circumflex artery; RSV, right sinus of Valsalva.

occurred only in one-third of coronary anomaly cases. ${ }^{9}$ However, AOCA may result in major cardiovascular events and sudden death as it was reported to be the second cause of sudden death among young athletes in USA ${ }^{10}$ and the third in Italy." The causes of symptoms, ischemia, and SCD in patients with AOCA have been proposed to be related to anatomical features of coronary artery such as acute angle takeoff, slit-like or fish-mouth-shaped orifice, interarterial or intramural course, and hypoplasia of the proximal part of artery.' It has been hypothesized that transient impairment of blood flow due to compression of the anomalous coronary artery between the aorta and pulmonary artery during exercise could cause myocardial infarction and/or SCD; however, the mechanism has not been completely understood yet. ${ }^{12}$

The prevalence of single coronary artery in the present study was at $0.05 \%$. Single coronary artery anomaly is a relatively uncommon, and the prevalence was reported between 0.024 and $0.044 \%$. Single coronary artery does not usually lead to any symptoms, and it is detected incidentally on coronary angiography or autopsy. Furthermore, this anomaly does not affect the life expectancy of these patients. However, in the presence of a major crossing artery between pulmonary artery and aorta, an increase in risk of sudden death might be seen. Additionally, this could be fatal if severe stenosis occurs at proximal segment of single artery. ${ }^{13,14}$

In the present study, the prevalence of coronary artery disease and acute coronary syndrome of patients was found to be 26.6 and $13.3 \%$, respectively. There are conflicting data about atherosclerosis in coronary anomalies. It was reported that coronary anomalies may lead to an increase in the development of premature atherosclerotic disease because of abnormal intracoronary hemodynamics, ${ }^{15}$ while the other research has not reported such a relation. ${ }^{16-18}$ Additionally, according to a research, the atherosclerosis was found to be less frequent in some anomalous vessel. In that study, patients who have an anomalous LAD were found to have significantly less atherosclerotic involvement compared to controls. Authors concluded that LAD mostly originated directly from RSV and had an anterior course to reach the anterior segment of the left ventricule. Therefore, the risk of development of atherosclerosis might decrease due to this long course of LAD without branching points. ${ }^{16}$ In our study, one of the cases was presented with an acute coronary syndrome. In the patient, single coronary artery was originating from RSV, and it was divided into RCA and LMCA. LMCA was long and giving two main branches as LAD and CX. LMCA was found to have stenosis at around $90 \%$ severity in mid-segment. A Standart JR guiding catheter was used, and angioplasty with stent implantation was performed successfully (Figure 2). However, AOCA with acute coronary syndromes can have some challenges such as prolonged procedures, which may lead to serious complications. For instance, the possibility of crossing atherosclerotic lesion and/or delivering balloon and stent implantation might be compromised due to lack of support by guiding catheter. ${ }^{19,20}$

In this study, ALCAPA, also known as Bland-Garland-White syndrome, was seen in one patient $(0.01 \%$ or $6.6 \%$ of all anomalies). She was a 46-year-old woman presented with congestive heart failure. Her transthoracic echocardiography showed a decreased left ventricular ejection fraction at 30\%. Coronary angiography showed a giant tortuous RCA arising from RSV and extending collaterals to the left coronary system (Figure 3). Left coronary arteries could not be visualized with aortography. The CT angiogram showed the anomalous origin of the left coronary artery arising from the main pulmonary trunk (Figure 4). She underwent a surgery for reimplantation of the left coronary artery trunk onto the aorta. ALCAPA is a rare phenomenon that occurs in I in 300,000 live births. Congestive heart failure or myocardial failure develops in most of the patients with this anomaly during early infancy period, and mortality rates reach up to $90 \%$ for infants in the first year of life if ALCAPA is not treated. Patients can survive if collateral channels develop between normal RCA and the anomalous left coronary system as seen in our case., ${ }^{6,21-23}$ Therefore, a dual coronary artery supply through reimplantation of the left coronary artery trunk onto the aorta for all patients with ALCAPA is a Class I recommendation.'

Additionally, there is another worth mentioning issue regarding imaging of coronary anomalies. Although coronary angiography is the gold standard diagnostic technique for coronary artery disease, it has some limitations for the evaluation of 


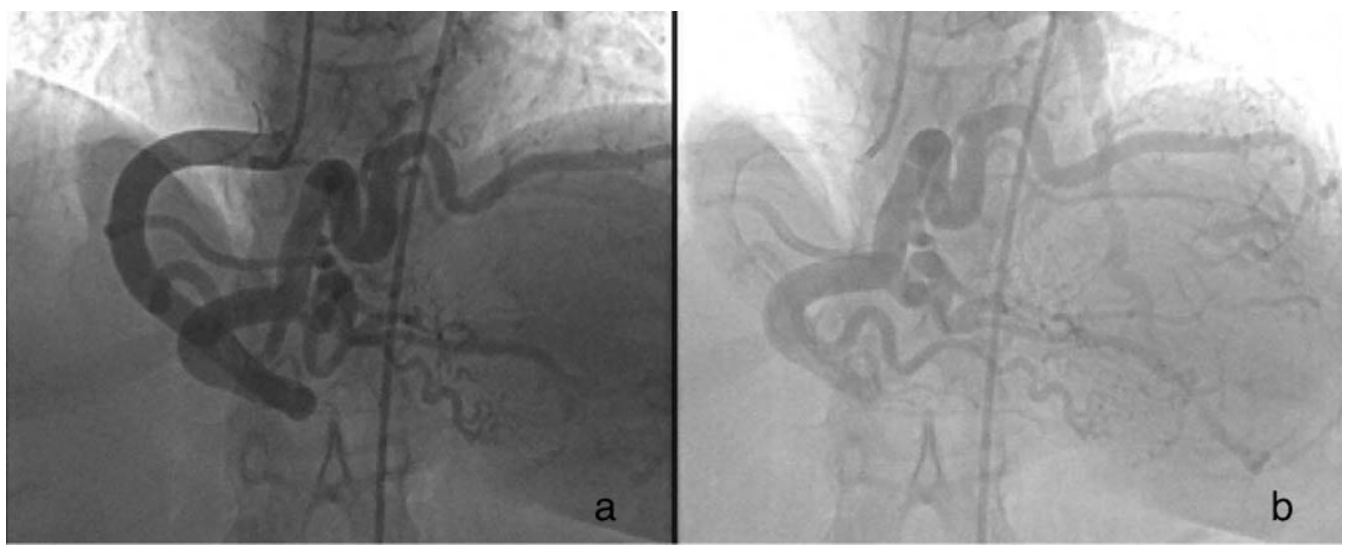

Figure 3. ALCAPA also known as Bland-Garland White syndrome. (a) Coronary angiography showed a giant tortuous RCA arising from RSV and (b) extending collaterals to the anomalous LCA.

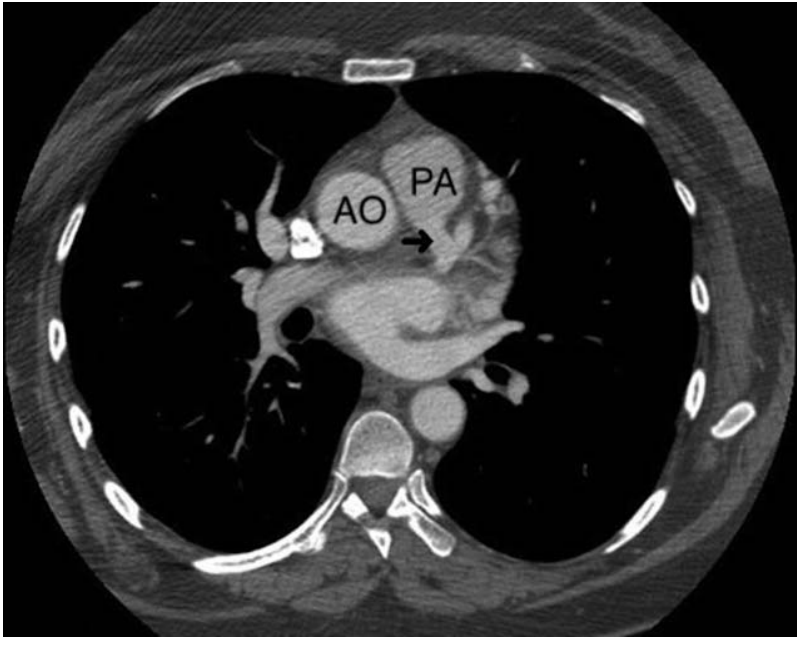

Figure 4. CT angiogram showed the anomalous origin of the LMCA arising from the main pulmonary trunk (arrow). PA, pulmonary artery; $\mathrm{AO}$, aorta; RCA, right coronary artery; RSV, right sinus of Valsalva; LMCA, left main coronary artery.

coronary artery anomalies. Conventional coronary angiography has limited capacity in terms of providing the threedimensional course of arteries and describing their precise relationship to neighboring anatomic structures such as pulmonary artery and aorta. Hence, multidetector CT angiography is usually necessary to delineate the proximal course and ostial origin of anomalous coronary arteries as a complementary imaging technique. ${ }^{24,25}$

In conclusion, AOCAs are rare congenital cardiovascular anomalies as the prevalence was found at $0.18 \%$ in the present study. The most commonly seen anomaly is the origin of CX artery directly from RCA or through a separate ostium from RSV. Anomalous origin of coronary arteries can complicate coronary interventions or cardiac surgeries. Therefore, being aware of coronary anomalies might be helpful for invasive cardiologists in terms of diagnosis and avoiding complications.
Ethics Committee Approval: Ethical committee approval was received from Gaziantep University Medical Faculty, Cardiology Department (study protocol code: 2018/331).

\section{Informed Consent: N/A}

Peer-review: Externally peer-reviewed.

Acknowledgements: The author would like to thank Dr. Murat Sucu, Dr. Ertan Vuruşkan, Dr. Irfan Veysel Düzen and Dr. Gökhan Altunbaş for their valuable contributions.

Conflict of Interest: The author has no conflicts of interest to declare.

Financial Disclosure: The author declared that this study has received no financial support.

\section{REFERENCES}

I. Stout KK, Daniels CJ, Aboulhosn JA, et al. AHA/ACC guideline for the management of adults with congenital heart disease: A report of the American College of Cardiology/American Heart Association Task Force on clinical practice guidelines. J Am Coll Cardiol. 2018;139(14):e698-e800.

2. Turkvatan A, Guray Y, Altinsoy D. Multidetector computed tomography imaging of coronary artery anomalies. Cardiol Young. 2013;23(5):661-674. [CrossRef]

3. Rabelo DR, Barros MV, Nunes Mdo C, Oliveira CC, Siqueira MH. Multislice coronary angiotomography in the assessment of coronary artery anomalous origin. Arq Bras Cardiol. 2012;98(3):266-272. [CrossRef]

4. Namgung J, Kim JA. The prevalence of coronary anomalies in a single center of Korea: Origination, course, and termination anomalies of aberrant coronary arteries detected by ECG-gated cardiac MDCT. BMC Cardiovasc Disord. 2014;14:48. [CrossRef]

5. Yuksel S, Meric M, Soylu K, et al. The primary anomalies of coronary artery origin and course: A coronary angiographic analysis of 16,573 patients. Exp Clin Cardiol. 2013;18(2):121-123.

6. Cheng $Z$, Wang $X$, Duan $Y$, et al. Detection of coronary artery anomalies by dual-source CT coronary angiography. Clin Radiol. 2010;65(I0):815-822. [CrossRef]

7. Perez-Pomares JM, de la Pompa JL, Franco $D$, et al. Congenital coronary artery anomalies: A bridge from embryology to anatomy and pathophysiology-A position statement of the development, anatomy, and pathology ESC working group. Cardiovasc Res. 2016;109(2):204-216. [CrossRef] 
8. Frescura C, Basso C, Thiene G, et al. Anomalous origin of coronary arteries and risk of sudden death: A study based on an autopsy population of congenital heart disease. Hum Pathol. 1998;29(7):689-695. [CrossRef]

9. Palmieri $\vee$, Gervasi S, Bianco $M$, et al. Anomalous origin of coronary arteries from the "wrong" sinus in athletes: Diagnosis and management strategies. Int J Cardiol. 2018;252:13-20. [CrossRef]

10. Maron BJ, Doerer JJ, Haas TS, Tierney DM, Mueller FO. Sudden deaths in young competitive athletes: Analysis of 1866 deaths in the United States, 1980-2006. Circulation. 2009;119(8):1085-I092. [CrossRef]

II. Corrado D, Basso C, Rizzoli G, Schiavon M, Thiene G. Does sports activity enhance the risk of sudden death in adolescents and young adults? J Am Coll Cardiol. 2003;42(II):1959-1963. [CrossRef]

12. Erol C, Seker M. Coronary artery anomalies: The prevalence of origination, course, and termination anomalies of coronary arteries detected by 64-detector computed tomography coronary angiography. J Comput Assist Tomogr. 2011;35(5):618-624. [CrossRef]

13. Kamana VK, Ramachandran P, Krishnan AM, Chowdary RK, Malpe UP. Anomalous single coronary artery presenting with acute myocardial infarction. J Clin Diagn Res. 2016;10(12):OD0IOD02. [CrossRef]

14. Vural A, Aksoy H, Karagoz A, Dindar B. Successful primary coronary angioplasty for acute inferior myocardial infarction in a patient with Rll-type single coronary artery. BMJ Case Rep. 2015. DOI: 10.1136/bcr-20l4-208325.

15. Samarendra P, Kumari S, Hafeez M, Vasavada BC, Sacchi TJ. Anomalous circumflex coronary artery: Benign or predisposed to selective atherosclerosis. Angiology. 2001;52(8):521-526. [CrossRef]

16. Canga Y, Guvenc TS, Karatas MB, et al. Congenital coronary artery anomalies in adults: Review of III cases from a singlecentre experience. Cardiol Young. 2017;27(6):1041-1050. [CrossRef]
17. Suryanarayana P, Kollampare S, Riaz IB, et al. Presence of anomalous coronary seen on angiogram is not associated with increased risk of significant coronary artery disease. Int $J$ Angiol. 20l4;23(4):243-246. [CrossRef]

18. Eid AH, Itani Z, Al-Tannir M, Sayegh S, Samaha A. Primary congenital anomalies of the coronary arteries and relation to atherosclerosis: An angiographic study in Lebanon. J Cardiothorac Surg. 2009;4:58. [CrossRef]

19. Marchesini J, Campo G, Righi R, Benea G, Ferrari R. Coronary artery anomalies presenting with ST-segment elevation myocardial infarction. Clin Pract. 20Il;(4):el07. [CrossRef]

20. Hong MY, Shin DH, Kwon JH, et al. Anomalous separate origin of left anterior descending coronary artery: Presented as acute anterior myocardial infarction. Korean Circ J. 2013;43(6):408-4I0. [CrossRef]

21. Kochar A, Kiefer T. Coronary artery anomalies: When you need to worry. Curr Cardiol Rep. 2017;19(5):39. [CrossRef]

22. Heermann $P$, Heindel W, Schulke C. Coronary artery anomalies: Diagnosis and classification based on cardiac CT and MRI (CMR)-From ALCAPA to anomalies of termination. Rofo. 2017;189(I):29-38. [CrossRef]

23. Quah JX, Hofmeyr L, Haqqani $H$, et al. The management of the older adult patient with anomalous left coronary artery from the pulmonary artery syndrome: A presentation of two cases and review of the literature. Congenit Heart Dis. 2014;9(6):El85-El94. [CrossRef]

24. Ghadri JR, Kazakauskaite E, Braunschweig S, et al. Congenital coronary anomalies detected by coronary computed tomography compared to invasive coronary angiography. BMC Cardiovasc Disord. 20|4;|4:8I. [CrossRef]

25. Opolski MP, Pregowski J, Kruk M, et al. Prevalence and characteristics of coronary anomalies originating from the opposite sinus of Valsalva in 8,522 patients referred for coronary computed tomography angiography. Am J Cardiol. 20I3;III(9):I36I-I367. [CrossRef] 